\title{
Effect of testos terone enanthate on the growth rate of large white pigs reared in South-West Nigeria
}

\author{
A. O. Ladokun
}

Department of Animal Physiology, University of Agriculture, Abeokuta, Nigeria

bimboladox@gmail.com, ladokunao@funaab.edu.ng

\begin{abstract}
A total of 48 large white pigs were used in an experiment to investigate the use of exogenous testosterone on the growth of pigs. The pigs were randomly selected as day old piglets, balanced for weight with equal number for each sex, and allotted to two treatment groups, T1, which received Testosterone Enanthate (TE), intramuscularly, weekly, for 24 weeks and T2, the control, which received no hormone but blank injections. Dosage was based on live weight $(1.2 \mathrm{mg} / \mathrm{kg}$ live weight). Corn oil served as the vehicle. The parameters measured include Total weight gain (TWG), Average Daily Gain (ADG), Average Daily Feed Intake (ADFI) and Feed Conversion Ratio. The results obtained showed that exogenous testosterone increased weight gain significantly $(p<0.05)$ in both sexes than their respective controls. The same trend was observed for feed intake and feed conversion. Exogenous testosterone also indicated pronounced sex effect on the pigs in this study with males having significantly $(p<0.05)$ higher values than females. It can be concluded from this study that exogenous testosterone can be used to accelerate growth thereby finishing the pigs early. A withdrawal period of 4 weeks before slaughter is however recommended.
\end{abstract}

Key words: Testosterone, Large White, Pigs, Growth, exogenous

\section{Introduction}

Pig keeping contributes to national development from the immediate provision of pig meat (pork) for human consumption as a practical means by which the animal protein intake of the average Nigerian can be increased within a short time (Madubuike, 1992). The advantages of pig production over other livestock species have been well documented (Dafwang, 2010). The most outstanding advantages, are those of prolific fecundity and its omnivorous feeding habit which enables it to survive in a very wide range of feedstuffs, it is estimated that over $90 \%$ of the pig population of $3,410,000$ (FLDPCS, 1991) are found in rural and semi-urban centres of the country. Despite these seemingly outstanding qualities of swine, there is a further need to development that will enhance swine production in the tropics.

Swine represents an important segment of the food animal industry throughout the world. Pork is an important source of dietary protein for humans and is the most widely consumed red meat in the world (Cromwell, 1991). Administration of exogenous hormone sources have been reported to increase growth rate, improve feed efficiency and change carcass composition (Machlin, 1972; Chung et al., 1985, Etherton, et al. 1986). As the human population increases, there is the need to properly harness exogenous hormones which have the ability to influence growth parameters without negatively affecting 
carcass quality and compromising the health of consumers.

This study was carried out to investigate the effect of exogenous testosterone (testosterone enanthate) on growth rate of large white pigs in south western Nigeria.

\section{Materials and Methods}

The experiment was carried out at the Piggery unit (physiology) Teaching and Research Farm, University of Ibadan, Ibadan.

A total of 48 large white pigs were used for this experiment consisting of 24 males and 24 females. Half the numbers of each sex (12) were used as experimental control animals with blank injections administered. At birth, the piglets were weighed and randomly allotted to the different treatment groups and the control. Identification was by the use of permanent colour markers to inscribe treatment or experimental codes and numbers (e.g. TM1 was for male piglet number 1 injected with testosterone). The hormone injections were obtained from Veterinary Pharmacy shops located in Ibadan. The injections were administered by deep intra-muscular injections in the thigh muscles of the hind-legs. The dosage per pig was $1.2 \mathrm{mg}$ testosterone enanthate per kilogram body weight and it was carried out between the hours of 7.am and 8.am.

The experimental Design employed was the randomized complete block design (twoway analysis of variance). Sex was the blocking factor.

Statistical Model: $Y_{i j}+\mu+\beta_{i}+T_{j}+\epsilon_{i j}$ where:

$\mathrm{Y}_{\mathrm{ij}}=$ individual observation for the $\mathrm{jth}$ treatment in the ith block

$\mu=$ general mean

$\beta_{\mathrm{i}}=$ effect of the ith block (sex)

$\mathrm{T}_{\mathrm{j}}=$ effect of the jth treatment (testosterone injection)

$\epsilon_{\mathrm{ij}}=$ experimental error
From the second week of experiment, the piglets were served creep feed to complement suckling of sow's milk.

\section{Results and Discussion}

Table 1 shows the growth performance of pigs injected with testosterone enanthate and their untreated controls. The parameters evaluated include, Total weight gain (TWG), Average Daily Gain (ADG), Average daily feed (ADF) and Feed /gain (Feed conversion FCR).

At birth, which marked the beginning of the experiment, the pigs were balanced for weight. At 5 weeks of age, the results showed that testosterone-injected female pigs had higher and significant TWGs and ADGs than their unijected female counterparts female. ADF and FCR values for testosterone-treated females were significantly better than the control animals. This trend was observed for the females throughout the duration of the experiment. For the males however, there were no significant differences for TWG, ADG, ADF and FCR at 5 weeks. At 10 weeks, 20 weeks and 24 weeks, testosterone treated males showed significantly higher TWG and ADG and better ADF and FCR. Comparison of the male and female treated pigs showed significant differences due to sex effect from weaning to 24 weeks when the experiment was terminated.

Figure 1 shows the periodic live weight changes in testosterone-injected pigs and their untreated controls. At birth all the pigs had similar live weight (controls and treated). At 5 weeks, pigs without hormone treatment had significantly lower live weight than treated female and live weight for female were significantly lower than for males at this period. The live weight for control males and treated males were not significantly different at this period. At 10 weeks, control females still had 
A. O. Ladokun

Table 1: $\quad$ Effect of exogenous testosterone on growth performance of large white pigs

\begin{tabular}{|c|c|c|c|c|c|c|c|}
\hline \multirow[t]{2}{*}{ Sex } & \multirow[t]{2}{*}{ Treatment } & \multirow[t]{2}{*}{ Parameter } & \multicolumn{5}{|l|}{ Weeks } \\
\hline & & & 0 (Birth) & 5 (Weaning) & 10 & 20 & 24 \\
\hline \multirow{9}{*}{$\mathrm{F}$} & & TWG (kg) & $1.04 \pm 0.02 *$ & $5.13 \pm 0.05^{b}$ & $8.50 \pm 0.04^{b}$ & $32.92 \pm 0.08^{b}$ & $36.20 \pm 0.09^{b}$ \\
\hline & & ADG (gm) & - & $147 \pm 14$ & $243 \pm 24^{b}$ & $471 \pm 24^{b}$ & $319 \pm 18$ \\
\hline & & $\mathrm{ADF}$ & - & - & $450 \pm 21$ & $910 \pm 34$ & $910 \pm 33$ \\
\hline & $\mathrm{C}$ & FCR & - & - & $1.9^{\mathrm{a}}$ & $1.9^{\mathrm{a}}$ & $2.8^{\mathrm{a}}$ \\
\hline & & TWG (kg) & $1.04+0.02$ & $6.35+0.04^{\mathrm{a}}$ & $10.74+0.06^{\mathrm{a}}$ & $40.87+0.06^{\mathrm{a}}$ & $44.02+0.12^{\mathrm{a}}$ \\
\hline & $\mathrm{T}$ & ADG (gm) & - & $181 \pm 17$ & $307 \pm 23^{a}$ & $584 \pm 26^{\mathrm{a}}$ & $457 \pm 24$ \\
\hline & & ADFI & - & - & $500+21$ & $938+34$ & $938+34$ \\
\hline & & FCR & - & - & $1.6^{\mathrm{b}}$ & $1.6^{\mathrm{b}}$ & $2.0^{\mathrm{b}}$ \\
\hline & & TWG (kg) & $1.05 \pm 0.02$ & $7.34 \pm 0.09$ & $13.80 \pm 0.48^{\mathrm{b}}$ & $35.39 \pm 0.08^{b}$ & $38.59^{\mathrm{b}} \pm 0.09$ \\
\hline \multicolumn{8}{|l|}{ M } \\
\hline & $\mathrm{C}$ & ADG(g) & - & $210 \pm 18$ & $397 \pm 13$ & $506 \pm 24^{b}$ & $460 \pm 19$ \\
\hline & & ADF I(g) & - & - & $620+31$ & $1400+38^{b}$ & $1400+38^{b}$ \\
\hline & & FCR & - & - & 1.6 & 2.7 & $3.04^{\mathrm{a}}$ \\
\hline & $\mathrm{T}$ & TWG (kg) & $1.06 \pm 0.02$ & $7.48 \pm 0.11$ & $13.59 \pm 0.07^{\mathrm{a}}$ & $42.42 \pm 0.11^{\mathrm{a}}$ & $46.62 \pm 0.13^{\mathrm{a}}$ \\
\hline & & ADG (gm) & - & $214+18$ & $388+22$ & $606+26^{\mathrm{a}}$ & $600+26$ \\
\hline & & ADFI(g) & - & - & $618+30$ & $1665+41^{\mathrm{a}}$ & $1666+41^{\mathrm{a}}$ \\
\hline & & FCR & - & - & 1.6 & 2.7 & $2.7^{\mathrm{b}}$ \\
\hline & & TWG (kg) & $1.05+0.02$ & $6.35+0.04^{\mathrm{b}}$ & $10.74+0.06^{\mathrm{b}}$ & $40.54+0.10^{b}$ & $44.02+0.12^{\mathrm{b}}$ \\
\hline Dort & TF & ADG(g) & - & $181 \pm 17$ & $307+23^{b}$ & $584+26$ & $457 \pm 24$ \\
\hline & & ADF I (g) & - & - & $500 \pm 21^{\mathrm{b}}$ & $938 \pm 34^{\mathrm{b}}$ & $938 \pm 34^{\mathrm{b}}$ \\
\hline & & FCR & - & - & 1.6 & 1.6 & 2.0 \\
\hline & & TWG (kg) & $1.05 \pm 0.02$ & $7.48 \pm 0.11^{\mathrm{a}}$ & $13.59 \pm 0.07^{\mathrm{a}}$ & $42.42 \pm 0.04^{\mathrm{a}}$ & $46.62 \pm 0.13^{\mathrm{a}}$ \\
\hline & TM & ADG(g) & - & $214+18$ & $388+22^{\mathrm{a}}$ & $606+26$ & $600+26$ \\
\hline & & ADF I(g) & - & - & $618 \pm 30^{\mathrm{a}}$ & $1665 \pm 41^{\mathrm{a}}$ & $1666 \pm 41^{\mathrm{a}}$ \\
\hline & & FCR & - & - & $1.6^{-}$ & $2.7^{\mathrm{a}}-$ & $2.7^{\mathrm{a}}-$ \\
\hline
\end{tabular}

abc: Means in the same column with different superscripts differ significantly $(\mathrm{P}<0.05)$ F: Female; M: Male; T: Testosterone injected group; C:

Blank injection control, TF: Testosterone injected female; TM: Testosterone injected male. * live weight at birth. ADG: Average Daily Gain; ADFI:

Average Daily Feed Intake; FCR: feed Conversion Ratio 


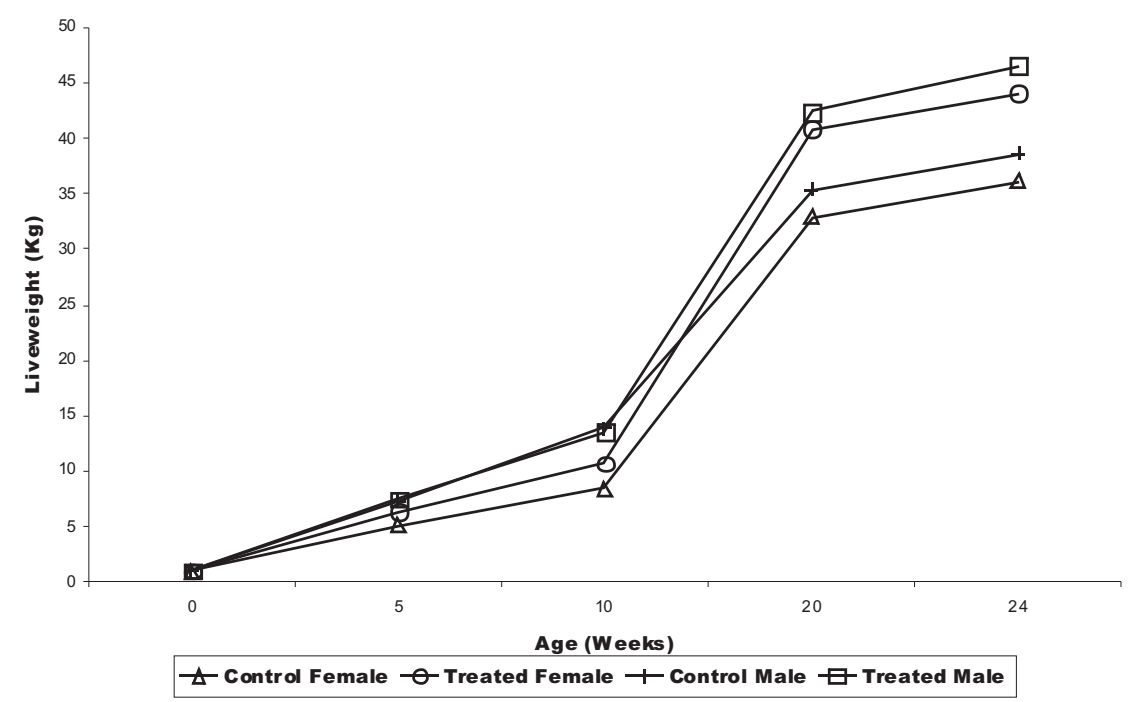

Fig.1 : Periodic Live weight changes in Testosterone injected Pigs

significantly lower live weight than hormone-injected females and the values for female pigs were still lower than that for males. There were no significant differences in live weight for control males and hormone-treated males. At 20 weeks however, both male and female pigs in hormone treatment had significantly $(p<0.05)$ higher live weights than the controls. Also, females on hormone treatment had significantly $(\mathrm{p}<0.05)$ higher live weights than control males, but lower than hormone-injected male. At 24 weeks of age, the live weights of hormone treated animals were significant $(p<0.05)$ than those of controls with blank injection.

The results of the experiment as indicated for growth performance in table 1 and figure 1 for control group pigs agrees with the findings of Eusebio, 1980 who examined the production performance of some major breeds of pigs in the tropics. He found out that Yorkshire (Large white) breed from weaning to growing finishing (80kg and above) had an average daily gain (ADG of 630g) and feed efficiency of 3.6. From the results, exogenous testosterone administered to pigs at day-old and once weekly through to 24 weeks of age on pigs gave a higher total weight gain (TWG), ADG, and average daily feed (ADF), a better feed intake and efficiency (FCR). Administering testosterone to pigs will lead to a shorter time from weaning to market weight. The close range in total weight gain at the end of the $24^{\text {th }}$ week between both treated sexes (TF and TM) show that both male and female pigs are able to tolerate and utilize exogenous testosterone in similar manner. The report of Lubritz et al. (1991) which showed positive correlations between testosterone production and growth is a substantial fact to back the findings of this study. In another similar study carried out by Bender et al. (2006), it was also reported that pigs selected for increased testosterone 
production grew faster and produced fatter carcasses than pigs selected for decreased testosterone. This fact is a further proof of increase in total weight gain (TWG), ADG, $\mathrm{ADF}$ and FCR recorded during this study. It has been established that physiological differences exist among intact males, and females: Intact males grow faster and are leaner than females. Thus the differences in TWG, ADF and FCR recorded in this study may be as a result of this fundamental fact (Cassady et al., 2004). Robison et al. (1994) found that 'high testosterone boars' (boars with higher than threshold blood testosterone) have greater ADG. Values recorded for both sexes in this study after exogenous testosterone administration may be supported with this finding. In some species, supplying exogenous testosterone to females and castrates increases their testosterone production to a level comparable with intact males (DeWilde and Lauwers, 1984; Montgomery et al., 2001).

\section{References}

Bender, J. M., See, M. T., Hanson, D. J., Lawrence, T. E. and Cassady, J. P. 2006. Correlated responses in growth, carcass, and meat quality traits to divergent selection for testosterone production in pigs. J Anim Sci. Vol. 84 (6) 1331-1337.

Cassady, J. P., Robison, O. W. Johnson, R. K. Mabry, J. W., Christian, L. L., Tokach, M. D., Miller, R. K. and Goodwin, R. N. 2004. National pork producers, council maternal line genetic evaluation: A comparison of growth and carcass traits in terminal progeny. J. Anim. Sci. 82:3482-3485.

Chung, C. S., Etherton, T. D. and Wiggings, J. P. 1985. Stimulation of Swine growth by Porcine growth hormone. J.Anim.Sci.60:118.
Dewilde, R. O., AND Lauwers, H. 1984. The effect of parenteral use of estradiol, progesterone, testosterone and trenbolone on growth and carcass composition in pigs. J. Anim. Sci. 59:1501-1509.

Eusebio, J.A. Pig production in the tropics. Longman Group Ltd., 1980.

Ethertone, T. D., Wiggins, J. P., Chung, C.S., Evock, C. M., Reblian, J.F and Walton, P. E. 1986. Stimulation of pig growth performance by Porcine Growth Hormone and Growth Hormone Releasing Factor. J. Anim. Sci. 63:1389.

Lubritz, D., Johnson, B. and Robison, $O$. W. 1991. Genetic parameters for testosterone production in boars. $J$. Anim. Sci. 69:3220-3224.

Machlin, L. J. 1972. Effect of Porcine Growth Hormone on growth and carcass composition of the pig. $J$. Anim. Sci. 35:794.

Madubuike, F. N. 1992. "Bridging the animal protein gap for rural development in Nigeria. The potential of pigs." Journal of Agriculture and Rural Development 5.1 (1992): 5-12.

Montgomery, T. H., Dew, P. F., and Brown, M. S. 2001. Optimizing carcass value and the use of anabolic implants in beef cattle. J. Anim. Sci. 79(E. Suppl.):E296-E306.

Robison, O. W., Lubritz, D. and Johnson, B. 1994. Realized heritability estimates in boars divergently selected for testosterone levels. J. Anim. Breed. Genet. 111:35-42.

Schinckel, A. P., Johnson, R. K. AND. Kittok, R. J. 1984. Testicular development and endocrine characteristics of boars selected for either high or low testis size. J. Anim. Sci. 58:675-685.

Received: $6^{\text {th }}$ February, 2012 Accepted: $2^{\text {nd }}$ February, 2013 